\title{
After Possession
}

\section{Iain MacKenzie}

Journal of French and Francophone Philosophy - Revue de la philosophie française et de langue française, Vol XXVII, No 1 (2019) pp 81-99

\author{
Vol XXVII, No 1 (2019) \\ ISSN 1936-6280 (print) \\ ISSN 2155-1162 (online) \\ DOI 10.5195/jffp.2019.849 \\ www.jffp.org
}

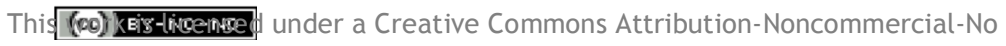
Derivative Works 3.0 United States License.

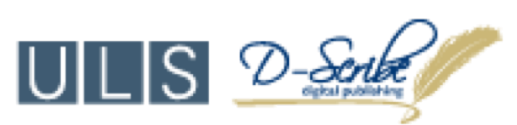

This journal is operated by the University Library System of the University of Pittsburgh as part of its D-Scribe Digital Publishing Program, and is co-sponsored by the University of Pittsburgh Press 


\title{
After Possession
}

\author{
Iain MacKenzie
}

University of Kent

The following questions may have an air of both familiarity and unfamiliarity for those who work within the tradition of modern European philosophy: 1) What if pots, pans, pliers and setsquares fell from the skies? 2) What if we have property in our own person? 3) What if people were simple enough to believe the first person who put a spade into the ground and said "this is mine"? 4) What if we are not in full possession of ourselves? 5) What if there is nothing, not a single thing, that is in possession of itself? These five questions trace a trajectory within the last five hundred years of modern European philosophy guided by a desire to understand - and also to halt - the steady encroachment of things. As we shall see, it is a trajectory that begins and ends in uncertainty. However, for most of the five hundred years it has been weaving its way through the Western canon of modern European thought those that defined this trajectory were guided by one deeply held certainty: if we don't possess ourselves, then the world of things will come to possess us. Indeed, it is not too much of an exaggeration to say that one of the key problems that defines the "modern" in modern European thought is the problem of possession.

This is not a new thought; it first appears in the work of C.B. Macpherson and in particular his interpretation of early modern English political thought, The Political Theory of Possessive Individualism: Hobbes to Locke. ${ }^{1}$ Hobbes, Harrington, Locke; all were driven by a shared belief in the self-possession of the individual person, a belief that both gave rise to deeply radical forms of liberalism that unhooked patriarchy and slavery from their allegedly naturalist bases and that also wove the idea of private property into the very fabric of the person, engendering and legitimating massive inequalities ever since. As Joseph Carens neatly summarises Macpherson's position: “The possessive individualist version of democracy denies and conceals the oppression and class domination inherent in a society based upon private and unequal - property." ${ }^{2}$ But Macpherson's analyses and diagnoses only captured part of a bigger picture. Historically, they did not reach back into 
Renaissance concerns with "the vanities" that shaped so many of the key themes of modernity but nor did they connect forward, so to speak, to the problem of possession that guided the philosophers of suspicion; Nietzsche, Marx and Freud. ${ }^{3}$ One of the consequences of this latter omission is that Macpherson did little to interrogate the grounds of his own position, such that he didn't reflect deeply enough upon the idea that his own socialist critique of liberalism was thoroughly reliant upon the same notions of self-possession and possessiveness that were the target of his critique. ${ }^{4}$ But is it possible to find a way of framing the problem of possession without falling back into partial and un-reflexive gestures? Moreover, if we can find a better way of framing this problem then the stakes are high: we can rethink the "modern" in modern European thought and, in doing so, we may, perhaps, find our way out of "the culture of possession" that sustains the "cultures of consumption" that shape our contemporary lives. ${ }^{5}$ A broader and deeper analysis of the problem may mean that there is a chance to think and to live after possession.

A seemingly unlikely text to turn to in this regard is Tristan Garcia's Form and Object: A Treatise on Things. ${ }^{6}$ It is unlikely because the text has been presented, to Anglophone readers at least, as a work of systematic philosophy that is a part of the contemporary turn away from the parochial concerns of modern critical theory. ${ }^{7}$ Nonetheless, in the following discussion, I shall explicate and defend four claims that bring it back into contact with this critical tradition: 1) that Garcia's Form and Object can be read, profitably, within this tradition of reflection upon the nature of possessions, selfpossession and possessiveness; 2) that to read the book in this way is to see Garcia as the French heir to McPherson although it will be argued that what this amounts to is that while McPherson was the anti-Locke, so to speak, Garcia is the anti-Rousseau; 3) that this framing has significant consequences for our reception of Form and Object in that it can be understood as a book that not only marks a moment in debates surrounding speculative realism and object oriented ontology but that it also, and primarily, marks an important moment in debates about the encroachment of things and the culture of possession that, in part, defines modernity; 4) that there is a novel ontological position within Form and Object, one that is neither relational nor individualist, that presents a challenging account of "the chance and the price" of living after possession and how to overcome the deleterious effects of contemporary consumer societies.

In order to make sense of these claims, I will sketch out the trajectory of thought oriented by the problem of possession within which, as will be argued, we can locate Garcia's book. I will then demarcate what I take to be the central problem addressed by Garcia - under the conceptual banner of "the compact" or the "principle of compactness" - and consider how his analyses decisively reorient the problem of possession through his controversial yet perceptive discussion of the nature of things and objects. What is at stake, I will argue, is whether or not we can conceive of a critique 
of possessiveness that does not rely upon either a relational or an individualistic ontology. In the end, it will be concluded that Garcia's own cautious, uncertain approach offers a compelling vision of both the price we may pay by giving up on self-ownership and the chance that may be afforded us if we have the courage to think after possession.

\section{The Problem of Possession: The First Four Questions}

In his Garcian Meditations, Jon Cogburn introduces Garcia's particular brand of realism by way of a "Whig history" that enables us to situate it within "dialectical space" in order to get a "sense of what is at stake." ${ }^{8}$ It is a similar gesture that orients this discussion, even though the dialectical space is construed differently. Where Cogburn begins his Whig history with Plato's myth of the cave in order to demarcate philosophy's perennial concern with the competing claims of realism and idealism so as to situate Garcia's text as an important contribution to this debate, I shall draw a more local or limited historical frame, that of the modern concern with the rise of things and their seeming capacity to dominate human life. In doing so, I do not disagree with Cogburn's framing of Garcia's contribution; indeed, much of what I will draw upon in the following discussion is deeply indebted to his insightful reading of Garcia's contribution as a metaphysician. However, as will become apparent as this discussion unfolds, framing Garcia's project as a contribution to modern European thought does allow us to focus on elements of his work that Cogburn's presentation does not foreground. Namely, we can profitably read Garcia's Form and Object as concerned with the problem of possession that has run through modern European thought and therefore consider it as a (perhaps surprising) book of critical theory, without diminishing its ostensible metaphysical project (so ably interrogated by Cogburn). This framing, a more critically oriented Whig history, can be given by considering the dialectical trajectory contained within the first four questions set out above.

Question 1: What if pots, pans, pliers and setsquares fell from the skies? And more: bellows, rakes, stools, ladders, bagpipes and many unidentified objects. This question is inspired by Leonardo da Vinci's work, A Cloudburst of Material Possessions, drawn circa 1510-13. ${ }^{9}$ This image is a startling demonstration of the Renaissance concern with the rapidly expanding world of things, tools, objects, possessions. But it is not clear what is at stake. Some years before this sketch, Savoranola had decisively come down on the side of the modest man in his "bonfire of the vanities": an unambiguous defence of the necessary relationship of modesty to Godliness. ${ }^{10}$ In his sketch, da Vinci is much less certain about what it is that is happening in the world of things, what it is doing to us, and what we may do in return. The objects are typically tools, functional objects, not Savoranola's "luxuries"; the objects are falling from the sky to earth rather than being burned on the earth to return them to the sky; there are no people crushed by this cloudburst; the whole thing seems 
to suggest an orderliness that speaks of the clash of naturalism and mechanism rather than earthliness and Godliness; it is an impersonal invasion of the functional object and thus unclear what the human response to it could possibly be; no bonfire of these tools, it seems, would ever halt the downpour. Da Vinci's subtlety is his uncertainty; this drawing catches a glimpse of the emergent world of modern capitalist economies, where our relationship to the functional objects that have made us able to build both palaces and hovels will no longer make sense, where they are no longer simply objects "for us" but objects that will simply rain down upon us.

Question 2: But what if we already have property in our own person? This Lockean question continues the errant line of this Whig history by virtue of providing the first properly philosophical response to da Vinci's cloudburst of material possessions. ${ }^{11}$ By the time of his Second Treatise on Government, Locke's $17^{\text {th }}$ Century Europe was beginning to feel the political shock waves of the rise of possessions: a whole class of people who felt that their possessions were theirs alone, inalienably, and not the property of the Monarch. But the new political language of consent was not enough to secure these possessions; another route had to be found. ${ }^{12}$ In one of the most dramatic twists of modern political theory, Locke declared that we already have property in our own person, that we therefore own what we do with our person, our labour, and that whatever we mix our labour with is rightfully ours. The cloudburst of material possessions could be harvested, channelled and turned into ever more possessions; simply pick up whatever nature has bequeathed and by virtue of having mixed your labour with it, it is your private property, by right, inalienably. The uncertainty of da Vinci's sketch is replaced, therefore, with Locke's certainty in our own self-possession and certainty therefore in our ability to reap the rewards of the cloudburst, at least for those emergent bourgeois that were hard working enough and endowed of the right spirit.

Question 3: What if people were simple enough to believe the first person who put a spade into the ground and said "this is mine"? It was already clear - for Savonarola but also for some of Locke's contemporaries, the puritans, for example - that legitimating the rampant accumulation of material possessions could have disastrous effects on social harmony. Yet, if burning the possessions was not the answer, and if simply denying oneself these possessions in the name of purity was not going to stop others from their accumulation, then how could the negative effects of possessiveness be overcome? It was Rousseau, in his "Discourse On the Origins and Foundations of Inequality Among Mankind," who diagnosed the problem of possessiveness and its resolution in genuinely social terms. ${ }^{13}$ The problem arose when the noble savages were simple enough to allow one of their kind to say "this is mine" and so the problem had to be addressed by a properly general act of will that would bring people back together in a conscious harmony of ends, one in which the institution of private property was 
thoroughly subordinate to those ends. By agreeing with each that we will do what is best for all rather than simply for those that possess property we will create a new political body in which each member is indivisible from the whole; a true social compact. ${ }^{14}$ This compact he defines as the total alienation of individual rights to the whole community; only then will the division and inequality brought about by the cloudburst of material possessions be held in check, not by the self-possession of the industrious bourgeois but by the total possession of all within the compact forged through the general will.

It seemed that these two forms of self-possession were the only way to respond to the cloudburst of material possessions: the self-possession of the individual and the self-possession of the community (and in many respects these two options still define our available responses to "cultures of consumerism"). Of course, both are responses "on the side of the subject," so to speak. Whatever else divided Locke and Rousseau, they agreed that the world of things, of possessions, required a completely self-possessed subject (individual or community) in order to control rather than be controlled by possessions.

Question 4: But what if we humans are not in full possession of ourselves? This was the question raised by the three great Victorian "masters of suspicion," to use Paul Ricoeur's phrase: Marx, Nietzsche, and Freud (and of course we could add the fourth, Darwin, though his project was less guided by "suspicion"). ${ }^{15}$ Each of these thinkers gave us reason to be suspicious of complete self-possession - either individual or collective. Perhaps the development of modes of production was out of our conscious control; perhaps we were driven by slavish resentments that we never realised; perhaps our desires never let us possess ourselves completely? This was the right line of inquiry, a line that pushed at the limits of our certainty about selfpossession in the search for a world after possession. And yet, each of these thinkers failed to step over the limits that they nonetheless recognized as constitutive of our deeply problematic relationship with possessions, because they each remained wedded, in the end, to the promise of a subjective resolution to come.

\section{The Problem of Possession: The Fifth Question}

One reason we know that the masters of suspicion never crossed this limit is that we now understand at least one of the questions to ask when it is truly crossed: what if nothing, not a single thing, is in possession of itself? This question is at the heart of Form and Object; to which I shall now turn.

Garcia begins Form and Object with a cautious statement: "Our time is perhaps the time of an epidemic of things." ${ }^{16}$ It is a time that reaches back to da Vinci's and it is a time he, da Vinci, might recognize. According to Garcia, there is "a kind of 'thingly' contamination of the present" and a "desubstantialisation" of things. ${ }^{17}$ But it also a time that Locke would 
acknowledge, a time of the "industrialisation of production," and even Rousseau could embrace Garcia's opening appeal to the fact that this contamination is hard to comprehend "without suffering from it." 18 And most assuredly, the masters of suspicion would dwell on Garcia's insistence that resisting this epidemic with all the usual means ready to hand is pointless, "a waste of time and effort." 19

And yet, even from the opening lines there is an air of difference about Garcia's ruminations, something that speaks to the problem of possession but that does so in an original way. On the one hand, he speaks of an epidemic things have some capacity to get inside of us and infect us like a virus, which immediately forces the uneasy thought that whatever we think is the difference between us and things it is not as clear cut as we typically presume. Just as the biologist can venture an organic continuity between humans and our viral co-existents, so Garcia seeks to establish a continuum between humans and things such that he proposes "a new model of the division of things - of things around us, of things in us, and of us among things." ${ }^{20} \mathrm{On}$ the other hand, the epidemic is "an epidemic of things," those abstracted metaphysical entities that we know, for many, are the most basic entities of all. How can such seemingly metaphysical and abstract entities infect us at all, and to such epidemic proportions that it defines our time? For Garcia, one of the key reasons for this is that we are not only things that think, but our thinking is itself a thing: "we must understand that by initially thinking about things we are not prevented from conceiving of our thought, language and knowledge as things equal to things thought, said and known." ${ }^{21}$ Garcia's opening framing of his project in Form and Object, therefore, already stakes out new ground for thinking about this epidemic, the ground being a maximally flat ontology of things.

The idea of a flat ontology - an ontological scheme in which there is no formal hierarchy between entities, which therefore attributes "an equal ontological dignity to each individuated thing" 22 - has become commonplace in many of the recent discussions around new materialism, speculative realism and object oriented ontologies. ${ }^{23}$ Although Harman notes that "this sort of 'flat ontology' has been familiar since the time of Alexius Meinong,"24 Garcia credits Manuel DeLanda's "rereading of Gilles Deleuze's philosophy" with the "idea of a 'flat ontology'." ${ }^{25}$ But where Meinong and Deleuze (and DeLanda) have faltered, Garcia seeks to tread confidently towards the "central claim" that "no classical determination - including the property of being non-contradictory, of being individuated, or of having identity or unity - is contained in our concept of the most unrestricted, emptiest thing and in the most formal possibility of a 'thing'." ${ }^{26} \mathrm{He}$ goes on: "we consider as inessential all that may characterise a thing until we have properly identified what defines it as a thing, and not as a consistent thing, individual thing, or one thing. We thus aim... at the being of de-determined things." ${ }^{27}$ The sheer reach of this claim is evident if we recall that Garcia's "things" not only include 
those conventional things, the number of which is rising to epidemic proportions "in our time," but also that which is "thought, said and known." That the latter may not be consistent, individuated or "one" is a challenge for even the flattest of flat ontologies.

Cogburn has presented the most compelling account of just how flat Garcia's flat ontology really is when he considers it in the context of Harman's characterisation of speculative realism. ${ }^{28}$ For Harman, speculative realists either reject the idea that "human-world" relations stand at the center of philosophy or the claim that all knowledge is finite and therefore unable to grasp reality in its own right. ${ }^{29}$ He aligns himself with the former but not the latter. But as Cogburn argues, Garcia rejects both claims: the human-world relation is not at the center of philosophy and yet knowledge of things, "in their own right," is possible. As Cogburn demonstrates, however, "the price to pay" for holding both of these positions is "the cost of characterising reality as a contradictory whole," a position that brings Garcia close to that of Graham Priest and Paul Livingstone to the extent that these thinkers also give an account of the contradictory (Priest) or paradoxical (Livingstone) nature of the whole. ${ }^{30}$

For all that he is not alone in thinking reality as a contradictory or paradoxical whole; the strangeness of Garcia's project is evident: "to prove that it is possible to describe the non-trivial qualities of a world of things lacking all qualities. Once the possibility of such a flat world of de-determined things is accepted, we must still prove its necessity, or at least its utility." ${ }^{31}$ As such, we should not let the flatness of Garcia's ontology of things distract us from its value in, one might say, a traditional sense. As noted above, Garcia clearly feels that there is "an epidemic of things" and he writes to convince people of this feeling; "the goal of this work is to bring those who do not yet share this feeling to admit it, and to propose to those who already admit it a way of ridding oneself of it." 32 And again: "This treatise is for those of us who love things, but who struggle in the face of their accumulation. It aims to put a thought to the test: a thought about things rather than a thought about our thought about things." 33 For all the strangeness of Form and Object, therefore, there is what I shall call a framing diagnostic-therapeutic dialectic organizing the discussion, albeit one that begins on the side of "that solitary something in each thing that can never be reduced to anything else" ${ }^{\prime 34}$ rather than on the side of the ailing subject. Perhaps that "solitary something," once diagnosed, offers up a way of "ridding oneself" of the feeling that there is an "epidemic of things"; or, at least, that we can rid ourselves of the feeling that this epidemic will infect the whole of humanity? It is one of the startling, and most original aspects of his work, that Garcia addresses this diagnostic-therapeutic dialectic from the side of things, so to speak. The gamble is that a better, by which in this case is meant a flatter, account of things will stop the epidemic. Not only does Form and Object offer up a new account of realism, as Cogburn eloquently argues, ${ }^{35}$ it offers up a new way of responding to the seemingly 
unstoppable rise of things that characterizes capitalist modernity; new, because no one prior to Garcia has thought to address this issue from the side of the thing. But how does he do this and what is to be gained by such a counter-intuitive philosophical gesture? In order to answer these questions, we must grasp the problem at the heart of Form and Object.

\section{The Compact: Garcia's Version of the Problem of Possession}

The self-avowed tasks of Form and Object are "a new model of the division of things" 36 and an "encyclopaedia and topography of the universe and objects." 37 The former is driven by the desire for a flat ontology, "in which any thing, sensu stricto, is equivalent to another thing ${ }^{\prime 38}$ and a formal system of the negative in order to provide the de-determined thing with its minimum definition: "a thing is nothing other than the difference between that which is in this thing and that in which this thing is." ${ }^{39}$ Therefore, the formal section of the book is not a way of sorting things, of ordering or boxing things that we may then regain control over them; rather, it is a minimal ontology of the internally divided nature of things. The latter encyclopedic task is rather different. According to Garcia, "an object is a thing that matters within another thing" ${ }^{\prime 0}$ and the task is to categorize and classify "the swarming universe" of objects with which we are more familiar: from the universe itself, through discussions of animals and humans, to culture, history and values and finally to the ages of life, and death. As he says, "the objective system is rich in content, in significations, in relations, in novelties, in accumulation, in choices, in disciplines, divided and multiplied in every direction, ad infinitum." 41 These two tasks - providing an account of a minimal, flat, ontology of things and a richly dimensional universe of objects - instill Garcia's project with the necessary tools for both the diagnosis of our "epidemic of things" and the therapeutic tools to consider what is at stake if we want to consider a life after possession.

Recalling that we humans are also things - that we are not only things that think but that our thought about things is also a thing - means that we too are internally divided, that we can only be defined, in a strict sense, as that difference between that which is in us and that in which we are. Moreover, as we are also objects in the sense that we are composed of things that matter in other things, so we can also be considered as members of the universe of objects that is "rich in content." But what is the critical import of these two claims? We have long since got used to the idea that human beings are divided within themselves and that in many respects our internal division is the result of our deep submersion within a world of things; at least to the extent that we have taken on board the insights of the philosophers of suspicion. What is innovative and controversial in Garcia's position, however, is twofold. First, 
that our "thingly" nature means that the epidemic of things can be diagnosed in a direct way; "the formal plane of thought enables us to cut short all epistemic, experiential, or enacted accumulation through simplicity." 42 Secondly, that there is no hope for the resolution of our submersion in the world of things that can be rooted in our subjective capacity to possess ourselves. Nothing in the richly textured universe of objects - things in things - can be found that will overcome the internally divided nature of things: be it, science, culture, spirit or philosophy itself. The universe of objects will not save us from the epidemic of things. According to Garcia, if we can and must consider ourselves to be things in order to avoid an ontological framework structured by unwarranted hierarchies and if things are defined by their lack of self-possession, then we can no longer be considered as beings capable of self-possession. The upshot is that any potential subjective resolution of the problem brought about by the epidemic of things can only be a chimera.

This chimerical search for resolution is given the name "compact" by Garcia. Unsurprisingly, given his division between a formal account of things and an encyclopaedic account of objects, there are two elements to his analyses of compactness. On the one hand, there is the claim that nothing can be compact "in itself." On the other hand, there is the claim that compactness exists but only as failure. The argument for the first claim is worth quoting at length:

If something is in itself, it is because there is confusion between "that which is" and "that which it is," between "that which is in this thing" and "that in which this thing is": "self." We are left with two possibilities. Either a minimal difference exists between the self "which is in" and the self "in which it is," in which case there is not one self but two selves. Or no difference exists between the self which is in and the self in which it is, in which case there cannot be something, since something is defined simply as the difference of the "in" between that which is in and that in which it is.

In the first case, two selves exist. In the second case, no selves exist. Something in "itself" either comprehends two things, or comprehends no thing. ${ }^{43}$

In summary, what we think about a thing and what we think about our thought about the thing will either create a split self incapable of being a single compact self or it will create a sense of self that can not think the very thing we are trying to think about. There are echoes of Meillassoux's critique of correlationalism and Harman's account of object oriented philosophy in this argument, though the differences between these positions are every bit as important. ${ }^{44}$ Meillassoux argues through the correlationist circle in order to reach a claim that is "after finitude" (we can know something about reality in 
its own right because we are the beings that think about these things). ${ }^{45}$ Harman, in contrast, rejects the idea that we have to go through the correlation of thinking and being to access objects, but argues that what we come to know about objects will always be finite because "finitude is not just a local spectre haunting the human subject, but a structural feature of relations in general including non-human ones." ${ }^{46}$ In contrast to both, Garcia does not think that we need to argue through the correlationist circle - at least we should take the chance of thinking that what is "thought, said and known" are themselves things - and that we can have unlimited access to the nature of things. Whereas Meillassoux's argument rests upon a positive, affirmative, rationalism and intellectualism, Garcia and Harman employ a rationalism of the negation, one in which the principle aim is that of de-determining objects. However, where Harman's is a form of negativity framed as constant withdrawal, Garcia's is a dialectical negation of a more open-ended nature. Hence Harman's objects are always withdrawing from themselves, even though they do in a sense exist in themselves, whereas Garcia's things are purely formal and in this sense do not exist in themselves at all. For Garcia, there is nothing, no thing, that has a compact nature.

As Cogburn notes, compactness is "perhaps the major antagonist in Garcia's text." 47 I suggest that we follow Garcia and drop the "perhaps": compactness, he says at the outset, "will be the adversary of our whole adventure of thought." ${ }^{48}$ But why is this lack of equivocation important? The answer to this question provides a route back to the second aspect of Garcia's critique of compactness; that it exists but always fails. We can see how this works if we ask a simple question: how does Garcia claim to know that the formal model of things he proposes has any veracity? Situating Garcia's critique of compactness solely as a response to the idea of the "in itself" risks presenting it as simply dogmatic. However, there are key elements to Garcia's project that suggest it should not be read as the simple presentation of a dogmatic system. From the opening pages we are invited to put the book down if we want to consider the conditions of thought that engender our thinking about things: "whoever expects philosophy to teach them about knowledge, consciousness, or individual and collective subjectivity more broadly, must be forewarned: they may be disappointed." ${ }^{49}$ The opening gambit, therefore, is to philosophise as if the Kantian epistemological turn had never happened. Garcia, however, goes on to develop this into a second claim; "our time is plagued by the metaphysics of access." ${ }^{50}$ None of the attempts to theorise "our methodological access to things" ${ }^{\prime 1}$ get us any closer to thinking about the "thingly contamination of the present." ${ }^{52}$ More particularly, these exercises in transcendental philosophy that define the post-Kantian philosophical milieu have, thirdly, hindered our attempts at understanding this contamination. If we are to understand how this contamination has taken place such that we are suffering from an epidemic of things then we must begin with a direct assault on the nature of things so that "we make no promises that we cannot keep." 53 All of which adds up to another reason why 
compactness is so essential for Garcia; it provides a pragmatic response to the problem of veracity. The test of the truth or not of his minimal metaphysics of things will be the extent to which it is useful in overcoming our objective sense of being possessed by things. Challenging, as thoroughly as possible, the idea that any thing - traditional things, subjects and our thought about both either is or may become compact in itself motivates the entirety of his response to the epidemic of things. That these attempts exist is undeniable, and yet for Garcia their existence is marked by failure; "compactness is the presence in the world of impossibility, its mode of possibility; failure. Nothing is impossible, but some thing (compactness) is possible if and only if it fails and fails in the world." ${ }^{54}$ Showing the failure of compact thinking is the main aim of the much longer second part of the book, the part that deals with the encyclopedia of objects. All of which is reason to think that Garcia's central philosophical claim - there is no thing in itself - is best read as a pragmatic and critical contribution to the problem of compactness, the idea that anything may possess itself, that defines modernity rather than as a direct riposte to Kant or as solely an intervention in the age-old debates between realism and idealism.

Having established this pragmatic and critical reading of compactness at the heart of his project, it then makes sense to claim that Form and Object is best approached as an anti-Rousseauean treatise. The real targets of the book are those who think that there is a manner of collective self-possession that will save us from the epidemic of things. As such, Garcia is both the heir to McPherson in that he accepts that no individual (thing or person) can be said to be truly self-possessed, while he is also a critic of McPherson to the extent that he questions the ideal of a form of social compact that can instantiate selfpossession at the level of the collective. Where the socialist McPherson found the roots of bourgeois liberalism in the possessive individualism of Hobbes, Harrington and Locke, Garcia finds the roots of all claims to self-possession, of Right and Left, in the presumption of the compact nature of things. The claim about the impossibility of compact things and the existence yet failure of compact objects functions as a critical perspective on both the possessive individualism so definitive of modernity - that we are what we possess - and also as a critical perspective that points to the necessary failure of all attempts to overcome neo-liberalism by appeal to our collective self-possession. Pitting the internal and interminable gap between that which is in a thing and that which a thing is against the social compact of Rousseau, Garcia constructs a perspective on the problem of possession that is highly original and compelling because it justifies its veracity pragmatically "for those of us who love things, but who struggle in the face of their accumulation." ${ }^{55}$ Moreover, this pragmatism is on the side of things and objects rather than individuals and collectives and, to this extent, it offers a route out of the impasses that beset the masters of suspicion. But what is this route beyond our cultures of possession and consumption and what hope, if any, does it offer if we are drawn to the prospect, as Garcia is, of a life after possession? 


\section{After Possession: The Problem, the Chance and the Price}

In making explicit the critique of possessiveness that guides Garcia's project, both as motivation and as pragmatic justification of his minimal metaphysics, I am claiming that it is better to situate Form and Object amongst the pantheon of modern critical theory than among the classics of "pure" metaphysics. While approaching the problem of possession from the side of the thing might seem to rule this out, to the extent that the critical tradition is usually defined by subjective reflexivity, it would be a mistake to introduce this arbitrary distinction if it blinded us to the force and contemporary relevance of Garcia's appeal to a life after possession. ${ }^{56}$ It is interesting to note, in this regard, that Harman reports that in their first conversation together Garcia remarked that his philosophical apprenticeship was shaped by his adolescent engagement with the Frankfurt School. ${ }^{57}$ For all that it is a text that Horkheimer and Adorno would barely recognise as critical theory, I have sought to make clear that the impact of this tradition is evident from the opening sentence of Form and Object: "our time is perhaps the time of an epidemic of things." 58 The critical interrogation of "our time" may then appear buried underneath the welter of metaphysical claims that define his approach to the thing, but for all that, it remains a text that makes its appeal to us, now, and that justifies its veracity in terms of how useful or not we find his critique of compactness, for us, now.

Indeed, we can now summarize the critical heart of Form and Object. For Garcia, there is nothing, no thing, that possesses itself (ourselves included) and, given this, all objects are collections of "things which matter in things" that may appear ordered in compact forms but that can, in fact, always be reordered differently because of their own internal division and the internal division within the things from which they are constituted. This is not only a critique of essentialism from the side of the thing rather than the subject, it is a critique of both liberal contracts and socialist compacts. Liberal contract theory rests upon the possessive individualism so astutely characterized and criticized by McPherson, and Garcia can be said to join McPherson in undermining the objective forms of politics that follow from this idea of compact individualism. Where Garcia's approach to these matters (that is, from the side of the thing) makes a difference is that he is also able to call into question the necessary appearance and failure of attempts to challenge possessive individualism in the name of a collective subject. In general, then, for all that it may seem to be as distant from such concerns as any book could be, Garcia's project is nonetheless a critique of all individualist claims to selfpossession (that which is in a thing) and of all collective claims to the intrinsic nature of relations (that in which a thing is) that underpin the hope of collective self-possession. 
There is, nonetheless, a problem in the critical apparatus that animates Garcia's project. As Livingstone puts it, "it is not clear how the overarching division between the formal world of things and the objective universe of objects itself is to be motivated...despite the detail and insight with which Garcia develops the internal characterisation of both domains, he says little about how the passage from one to the other is produced or traversed." ${ }^{59} \mathrm{I}$ have given one answer to this problem: Garcia's discussion is motivated by a strong, albeit heterodox, sense of critical intervention in the cultures of accumulation and possession that define our current age. Another response, which develops the first, is to recognize that all attempts to compact objects such as the individual, collectives, cultures, spirit and so on - do appear to be present in our world but only to the extent that they fail because of the intrinsically uncompacted nature of things. In this sense, part II of Form and Object is methodologically prior to part I: there is no metaphysically proper way to move from things to objects, such that we can only de-substantialise objects in order to reach a maximally flat ontology of things. But Livingstone's point is rather more cutting. How do objects appear at all, if there are only dedetermined things in our metaphysics of the world? I agree with Livingstone when he says that there is no clear account of this given by Garcia. Where I would add a different slant to Livingstone's problem is that this may not matter. To back up this claim, however, is to move Form and Object away from an interpretive framework that treats it solely as a metaphysical treatise that must build its claims from the bottom-up, so to speak. It is more in keeping with his project to treat Garcia as aligned to Badiou's subtractive metaontology: our ontological claims are only to be derived by subtracting all that is inessential from what is, in this case the objects of the world. ${ }^{60}$ Moreover, this interpretive move can also bring us to the final insight that can be garnered from Garcia's text: the chance and price to pay of living after possession.

Methodologically speaking, Garcia must assume that objects are simply present and that their presence in the universe can change. In a claim that puts him within and yet decisively at odds with the process philosophies of, for example, Whitehead and Deleuze, Garcia attributes such change in objects to events. ${ }^{61}$ The sense in which he joins the tradition of process philosophy is simply this: he treats the changes within objects as events that give us no reason to rest content with their apparent permanence; or compactness, in Garcia's terminology. Where he pits himself directly against such process philosophies is in how he treats events. Whereas process philosophies treat events as the condition of emergence for that which we encounter in our everyday world, Garcia is suspicious of such claims because he argues that such approaches can only lead to both a multiplication of emergent things and a reduction of those things to one, compact, notion of the event. His task, in contrast, is to retain a minimal account of things that does not lead to their rapid multiplication but that also avoids their reduction into a mystical sense of the event. Now that his notion of the event is brought into view, initially at 
least, we can see the critical purchase of his minimal ontology: "every ontology that privileges events over objects and things, or objects rather than things and events, or things to the detriment of objects and events, is groundless and systematically leads to compactness." ${ }^{62}$

His approach to avoiding ontologies that lead to compactness is to treat events as intensive variations in the presence of objects. Intensification, for Garcia, is the moment when the difference between what an object contains and that which contains them is changed. Such intensification occurs when objects "comprehend" each other. Comprehension is a technical term for Garcia that is defined as the sense objects make of each other. As such, objects are intensified at the moment of their comprehension, when they make sense of each other. There are philosophical conundrums that follow from this account of comprehension and intensification. ${ }^{63}$ For our purposes, though, the main point from a critical perspective is that such intensification is the moment of extended differentiation between that which is in a thing and that in which a thing is. It is, in short, the pulling apart of that which appears compact in order to expose its internal differences such that they can be reconstituted in new ways. Comprehension as a moment of intensification, therefore, is the critical motif that articulates Garcia's subtractive method without instantiating what he would see as a mystical privileging of thing, object or event. It is for this reason that we can say his analysis is more than an extension of the idea that notions of self-possession are socially constructed. For all that the reading of Form and Object developed above situates the book within a critical tradition, it is equally clear that there is no scope within Garcia's system for an appeal to "social construction" as this would require a claim about the compact nature of the social that is anathema to his position. It would be more in keeping with his approach to objects to claim that the outcome of his challenge to possessiveness leads toward the idea that all objects (individuals and collectives) exist within and between "overlapping and contradictory classes." ${ }^{64}$ However, in itself this claim does not fully express the critical dimension of his appeal to comprehension as a moment of intensification. Comprehension of our contradictory existence requires actively reconstituting the classes to which we belong. But to what end?

Garcia's critical response to the epidemic of things can now be articulated in terms of its purpose: all objects, ourselves included, can become more of what they are by intensifying the difference that makes them what they are that is, the difference between what they contain and what they are contained within. This intensification, we can now say on the basis of situating Garcia's argument within the modern tradition of the critique of self-possession, is the task of living a life without self-possession, or living a life after possession. There is a strong existentialist twist to this conclusion: "objective accumulation is our condition. We experience existential suffocation from it, but it also forms an opening allowing us to take in the world amidst objects." 65 
In ridding ourselves of the objective determinations of who we are, we are able to constitute our life in ways that avoid the dangers of compactness. In contrast to the existentialist, however, this life will never be authentic in the sense that might reintroduce a concern about a compact notion of identity, at either the individual or collective level. Garcia, we might say, is an existentialist of the internally divided thing. The intensive life requires resisting the idea that we are already self-possessed individuals and resisting the idea that we are individuals defined by our collective existence, thereby resisting any over-arching collective definition of who we are as collectively possessed beings. It is a call for a life of contradiction, of paradoxes, and a call to resist every objective attempt to remove these paradoxes. The price to pay for living after possession is the tragedy of never being able to reconcile oneself with oneself - but maybe it is a price worth paying given the disastrous effects of living under cultural, economic and political regimes based on the unsustainable idea of our ability to possess ourselves. A life after possession may be worth the price of it being a paradoxical and contradictory life.

${ }^{1}$ C. B. MacPherson, The Political Theory of Possessive Individualism: Hobbes to Locke (Oxford: Oxford University Press, 1962).

2 Joseph H. Carens, "Possessive Individualism and Democratic Theory: Macpherson's Legacy," in Joseph H. Carens (ed.) Democracy and Possessive Individualism: the intellectual legacy of C. B. Macpherson (Albany: SUNY Press, 1993), 1-18.

${ }^{3}$ Paul Ricoeur, Freud and Philosophy: An Essay on Interpretation (New Haven: Yale University Press, 1970).

${ }^{4}$ Admittedly, Macpherson's developed political theory is a more nuanced blend of the idealism of T. H. Green with the socialist theory that drives The Political Theory of Possessive Individualism. For a sympathetic account of his developed political philosophy and the role individualism plays within it see, Peter Lindsay, Creative Individualism: The Democratic Vision of C. B. Macpherson (Albany: SUNY Press, 1996). Virginia Held, "Freedom and Feminism" in Carens (ed) Democracy and Possessive Individualism, 137-154, makes a good case in support of the idea that neither Macpherson's diagnoses of possessive individualism nor his prescription for its cure sufficiently interrogate his own individualist foundations.

${ }^{5}$ Frank Trentmann, Empire of Things: How We Became a World of Consumers, from the Fifteenth Century to the Twenty-first (London: Allen Lane, 2016). 
${ }^{6}$ Tristan Garcia, Form and Object: A Treatise on Things, trans. Mark Allan Ohm and Jon Cogburn (Edinburgh: Edinburgh University Press, 2014).

${ }^{7}$ Chiefly, I have in mind Graham Harman's “Object Oriented France: The Philosophy of Tristan Garcia," Continent, vol. 5, No. 1, 2012, 6-21. While it provides an excellent summary of Form and Object, Harman's overview does little to situate the text as a commentary on "the epidemic of things" and therefore reduces the critical force of Garcia's text. A similar problem animates Nathan Brown's otherwise thorough review; Nathan Brown, "Speculation at the Crossroads," Radical Philosophy, 188, Nov/Dec 2014, 47-50.

8 Jon Cogburn, Garcian Meditations: The Dialectics of Persistence in Form and Object (Edinburgh: Edinburgh University Press, 2017). He attributes the "necessity" of such an approach in "contexts such as this" to Robert Brandom, Reason in Philosophy: Animating Ideas (Cambridge, MA: Harvard University Press, 2013).

${ }^{9}$ This pen and ink drawing is part of the Royal Collection (RCIN 912698) and can be viewed at: https://www.royalcollection.org.uk/collection/912698/a-cloudburst-ofmaterial-possessions (last accessed 31/05/17).

${ }^{10}$ For a good account of what was at stake in Savonarola's "bonfire of the vanities" see Paul Strathern, Death in Florence: The Medici, Savonarola and the Battle for the Soul of Man (London: Vintage, 2012).

11 John Locke, Two Treatises of Government, ed. Peter Laslett (Cambridge: Cambridge University Press, 1960). For a contemporary version of Locke's argument for individual self-possession, see Robert Nozick, Anarchy, State and Utopia (Oxford: Basil Blackwell, 1974).

12 It is well known that the immediate context of Locke's famous argument is as a response to Filmer's reductio ad absurdum argument about consent based accounts of legitimate private property relations. See, for example, Judith Richards, Lotte Mulligan and John K. Graham, “'Property’ and ‘People’: Political Usages of Locke and Some Contemporaries," Journal of the History of Ideas, vol. 42, No. 1 (1981) : 29-51. In the context of this discussion, it is claimed that Locke's argument for selfpossession is a key part of a constructed "Whig history" of dialectical debate; that is, not one of which he was aware of being a part.

13 Jean-Jacques Rousseau, "Discourse on the Origin and Foundations of Inequality Among Mankind," in Susan Dunn (ed.) The Social Contract and The First and Second Discourses (New Haven, Yale University Press, 2002).

14 "The Social Compact" is the title of Book 1, Section VI, of The Social Contract in the translation by G. D. H. Cole; The Social Contract and Discourses (London: J. M. Dent and Sons, 1973). The term "social compact" is used in order to highlight the 
connection to be drawn between Rousseau's concerns and those of Garcia. This phrase is sometimes translated as simply "social pact" but the meaning is the same.

15 Ricoeur, Freud and Philosophy. For an insightful discussion of Ricoeur's "hermenutics of suspicion" see Alison Scott-Baumann, Ricoeur and the Hermeneutics of Suspicion (London: Continuum, 2009).

${ }^{16}$ Garcia, Form and Object, 1.

${ }^{17}$ Garcia, Form and Object, 1.

18 Garcia, Form and Object, 1.

${ }^{19}$ Garcia, Form and Object, 1.

${ }^{20}$ Garcia, Form and Object, 2.

${ }^{21}$ Garcia, Form and Object, 3-4.

${ }^{22}$ Garcia, Form and Object, 4.

${ }^{23}$ For a good discussion see, Levi Bryant's, The Democracy of Objects (Ann Arbor: Open Humanities Press, 2011) in which he usefully characterises various approaches to flat ontology as those that reject "the existence of sovereign entities that condition all other entities without themselves being conditions," 94.

${ }^{24}$ Graham Harman, "Series Editor's Preface” in Tristan Garcia, Form and Object, xxiiixv, xxiv. See Cogburn, Garcian Meditations, 36-7, note 1, for an excellent summary of Garcia's position vis-à-vis Meinong.

${ }^{25}$ Garcia, Form and Object, 4.

${ }^{26}$ Garcia, Form and Object, 5.

27 Garcia, Form and Object, 5.

${ }^{28}$ Gogburn, Garcian Meditations, 21-30.

29 Graham Harman, Quentin Meillassoux: Philosophy in the Making, 2nd Edition (Edinburgh: Edinburgh University Press, 2015), 4.

30 That said, Cogburn is clear that differences remain between these thinkers; see, for example, his note on the difference between "things" in Garcia and "gluons" in Priest: Cogburn, Garcian Meditations, 152, note 10. Livingstone has written a sympathetic yet critical review of Form and Object that details some of his principal concerns: Paul Livingstone, "Formal Ontology and the Flat World: A Review of Tristan Garcia's Form and Object," Continental Philosophy Review 49 (2016): 545-553.

${ }^{31}$ Garcia, Form and Object, 5.

${ }^{32}$ Garcia, Form and Object, 1.

${ }^{33}$ Garcia, Form and Object, 2.

${ }^{34}$ Garcia, Form and Object, 8.

${ }^{35}$ Cogburn, Garcian Meditations.

${ }^{36}$ Garcia, Form and Object, 2. 
${ }^{37}$ Garcia, Form and Object, 6.

${ }^{38}$ Garcia, Form and Object, 5.

${ }^{39}$ Garcia, Form and Object, 13.

${ }^{40}$ Garcia, Form and Object, 146.

${ }^{41}$ Garcia, Form and Object, 152.

${ }^{42}$ Garcia, Form and Object, 6.

${ }^{43}$ Garcia, Form and Object, 63.

${ }^{44}$ See, for example, Quentin Meillassoux, After Finitude: An Essay on the Necessity

of Contingency (London: Continuum, 2009) and Graham Harman, Object-Oriented

Ontology: A New Theory of Everything (London: Pelican Books, 2018).

${ }^{45}$ Meillassoux, After Finitude.

${ }^{46}$ Harman, Quentin Meillassoux, 4.

${ }^{47}$ Cogburn, Garcian Meditations, 111.

${ }^{48}$ Garcia, Form and Object, 14.

${ }^{49}$ Garcia, Form and Object, 2.

${ }^{50}$ Garcia, Form and Object, 3.

${ }^{51}$ Garcia, Form and Object, 3.

${ }^{52}$ Garcia, Form and Object, 1.

${ }^{53}$ Garcia, Form and Object, 4.

${ }^{54}$ Garcia, Form and Object, 69.

${ }^{55}$ Garcia, Form and Object, 2.

${ }^{56}$ I note here that I am offering up what may appear to be a vague notion of the critical tradition as that which is simply engaged with current concerns. However, it is not my intention to deflate the idea of critique to that extent, but rather to suspend the presumption that critically oriented work must be defined by the exploration of the conditions of subjectivity, as usually conceived. Such suspension, moreover, is part of the post-Kantian tradition. And, finally, approaching Garcia in this way is legitimated to the extent that he conceives of the "traditional" subject in objective terms and then enquires into its conditions. Cogburn's "Introduction" makes a good case for including Garcia within a heterodox lineage of transcendental reflection that supports the idea that we should not rush to preclude him from the critical tradition as currently conceived: Garcian Meditations, 1-9.

${ }^{57}$ Harman, “Object Oriented France," 7.

${ }^{58}$ Garcia, Form and Object, 1.

${ }^{59}$ Livingstone, “Formal Ontology and the Flat World," 549.

${ }^{60}$ Alain Badiou, Being and Event (London: Bloomsbury, 2013). 
61 Each of the main secondary sources give interesting accounts of Garcia's relationship to process philosophy, and they do so in a broadly complimentary way which I draw upon in this paragraph. See Cogburn, Garcian Meditations, esp Chp. 5; Harman, "Object Oriented France"; Livingstone, "Formal Ontology and the Flat World."

${ }^{62}$ Garcia, Form and Object, 172.

${ }^{63}$ Cogburn, Garcian Meditations, 143-9.

${ }^{64}$ Garcia, Form and Object, 364.

${ }^{65}$ Garcia, Form and Object, 95. 